\title{
Performance Evaluation of Various Phase Change Materials for Thermal Energy Storage of A Solar Cooker via Numerical Simulation
}

\author{
Dede Tarwidia ${ }^{*}$, Danang Triantoro Murdiansyaha, Narwan Ginanjara
}

${ }^{a}$ Modeling and Computational Experiment Research Group, School of Computing, Telkom University

Jalan Telekomunikasi No. 1 Terusan Buah Batu, Bandung 40257, Indonesia

\begin{abstract}
In this paper, thermal performance of various phase change materials (PCMs) used as thermal energy storage in a solar cooker has been investigated numerically. Heat conduction equations in cylindrical domain are used to model heat transfer of the PCMs. Mathematical model of phase change problem in the PCM storage encompasses heat conduction equations in solid and liquid region separated by moving solid-liquid interface. The phase change problem is solved by reformulating heat conduction equations with emergence of moving boundary into an enthalpy equation. Numerical solution of the enthalpy equation is obtained by implementing Godunov method and verified by analytical solution of one-dimensional case. Stability condition of the numerical scheme is also discussed. Thermal performance of various PCMs is evaluated via the stored energy and temperature history. The simulation results show that phase change material with the best thermal performance during the first 2.5 hours of energy extraction is shown by erythritol. Moreover, magnesium chloride hexahydrate can maintain temperature of the PCM storage in the range of $110-116.7^{\circ} \mathrm{C}$ for more than 4 hours while magnesium nitrate hexahydrate is effective only for one hour with the PCM storage temperature around $121-128^{\circ} \mathrm{C}$. Among the PCMs that have been tested, it is only erythritol that can cook $10 \mathrm{~kg}$ of the loaded water until it reaches $100^{\circ} \mathrm{C}$ for about 3.5 hours.
\end{abstract}

Keywords: PCM, thermal performance, heat transfer, solar cooker, Godunov method, numerical simulation

Article History: Received June 22 ${ }^{\text {nd }}$ 2016; Received in revised form August 26 ${ }^{\text {th }}$ 2016; Accepted Sept 1 ${ }^{\text {st }}$ 2016; Available online

How to Cite This Article: Tarwidi, D., Murdiansyah, D.T, Ginanja, N. (2016) Performance Evaluation of Various Phase Change Materials for Thermal Energy Storage of A Solar Cooker via Numerical Simulation. Int. Journal of Renewable Energy Development, 5(3), 199-210. http://dx.doi.org/10.14710/ijred.5.3.199-210

\section{Introduction}

Energy issue is a crucial factor in the sustainability of human life. Conserving energy is very important because of limited energy resources. Renewable energies become the main consideration in domestic and industrial applications because of the deficiency of fossil fuels and rapid growth in conventional energy consumption (Handayani \& Ariyanti 2012). One of the renewable energies is solar energy which is produced by the unlimited resource. It is free and does not pollute environment so that it is very reasonable to use solar heat energy for daily use, such as cooking. However, the utilization of conventional solar cookers has some drawbacks. A restriction of the conventional solar cookers is that the cooking cannot be done during off- sunshine hours or late evening. To overcome the limitation, it is important to complement the solar cooker with a thermal energy storage unit. By utilizing the energy storage, it will be possible to cook food during off-sunshine hours or late evening. Moreover, by using PCM, it can increase productivity of fresh water until 20\% in pyramid solar still system (Ravishankar et al. 2013). Therefore, the PCM can be considered as thermal energy storage medium in solar cooker system. Muthusivagami et al. (2010) discussed the development of solar cookers with and without phase change material as thermal energy storage. In developing prototype of a solar cooker, it is important to select PCMs that have high thermal performance by considering their thermophysical properties such as melting temperature, density, thermal conductivity,

*Corresponding Author: +62227564108; fax: +62227565931

Email: dedetarwidi@telkomuniversity.ac.id 
specific heat, and latent heat of fusion. Besides, other properties such as toxicity, corrosiveness, and price should also be considered (Sharma et al. 2005).

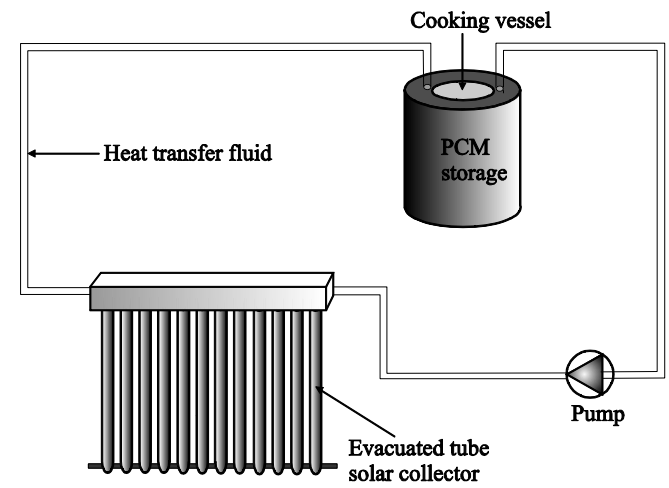

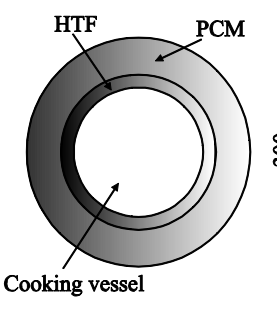

(b)

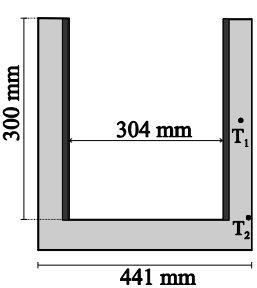

(c)

(a)

Fig. 1 Configuration of solar cooker with PCM as thermal energy storage. (b) Top view of PCM storage unit. (c) Vertical section and dimension of PCM storage unit.

A phase change material (PCM) is a substance able to change the phase from solid to liquid or vice versa. PCM has high latent heat of fusion so that it can store and release large amount of energy. The heat energy is absorbed and released when the material changes the phase. PCM is very suitable as thermal energy storage because of its capability to store heat energy. PCM can store 5-14 times more heat per unit volume than conventional storage materials (Sharma et al. 2009).

Several experiments were conducted to examine thermal performance of solar cooker with phase change material as thermal energy storage. Domanski et al. (1995) considered the possibility of cooking during offsunshine hours. In their experiment, stearic acid or magnesium nitrate hexahydrate was used as PCM. They concluded that parameters such as thermophysical properties of the PCM, solar intensity, and mass of cooking medium have strong effect on solar cooker performance. Furthermore, Buddhi et al. (1997) developed a cylindrical PCM storage unit with stearic acid as thermal energy storage while Sharma et al. (2000) used commercial grade acetamide. They compared thermal performance of the solar cooker with a conventional one. Their experimental results displayed that melting point of PCM should be in the range of $105-110^{\circ} \mathrm{C}$ for evening cooking. Buddhi et al. (2003) developed a PCM storage unit for a box-type solar cooker. Commercial grade acetanilide was used as a latent heat storage material. From their experiment, it was concluded that the late evening cooking is possible in a solar cooker with three reflectors and latent heat storage. Singh et al. (2015) conducted experimental comparison of different heat transfer fluid to assess thermal performance of a solar cooker. Kanimozhi et al. (2015) studied experimentally coconut oil (commercial grade) as phase change material in a box type solar
Conducting a direct experiment regarding to thermal performance of a PCM is an expensive work. Hence, some researchers evaluated thermal performance of solar cooker by numerical simulations. Khalifa et al. (1987) conducted numerical simulation to examine thermal performance of solar cooker where the solar energy is collected by spiral concentrator. Moreover, Costa et al. (1998) studied thermal performance of energy storage system with and without fins. They concluded that the magnitude of melt fraction with fins is more suitable than the system without fins. Chen et al. (2008) investigated numerically heat transfer of some PCMs used in a box-type solar cooker. In their simulation, stearic acid, magnesium nitrate hexahydrate, erythritol, acetamide, and acetanilide were used as thermal energy storage. According to their numerical results, it was observed that acetamide and stearic acid should be used as thermal storage in boxtype solar cooker. Najemi \& Boroushaki (2016) calculated heat losses in solar dish/Stirling system using mathematical modeling and simulation. Their simulation results were compared with experimental data of Eurodish system and showed a reasonable heat loss in Stirling engine and cavity receiver.

In this work, numerical simulation of various phase change materials, i.e. erythritol, magnesium nitrate hexahydrate, RT100, magnesium chloride hexahydrate, and paraffin has been conducted to evaluate their thermal performance for a solar cooker equipped with evacuated tube solar collector. The PCMs were chosen because their melting points are between $70-120^{\circ} \mathrm{C}$ which is relevant to domestic appliance. To determine appropriate PCM with high thermal performance, the selected PCMs are evaluated according to their stored energy and temperature history. In the previous study, some of these PCMs have been tested numerically for a thermal energy storage which consists of some small 
hollow cylinder PCMs and packed in a larger cylindrical tank (Tarwidi 2015) while the present study focus on numerical simulation of the thermal energy storage of a solar cooker which has been developed by Sharma et al. (2005). In Section 2, mathematical model to describe heat transfer and phase change problem in cylindrical PCM storage is discussed. Numerical solution of the mathematical formulation including the stability and numerical verification is presented in Section 3. The last, in Section 4 and Section 5, numerical simulation of the selected PCMs is presented and discussed.

\section{Mathematical Model}

The schematic design of solar cooker with thermal energy storage is adopted from experimental set up conducted by Sharma et al. (2005). The configuration of the solar cooker system is simply illustrated in Fig. 1(a). The main components of the system consist of evacuated tube solar collector, heat transfer fluid (HTF), pump, PCM storage, and cooking vessel. Top view and vertical section of PCM storage unit are presented in Fig. 1(b) and Fig. 1(c), respectively. At first, heat energy from sunrise is collected through solar collector component. From this device, heat energy is absorbed by heat transfer fluid and flowed out toward PCM storage unit. Hot fluid containing solar heat energy is received by phase change material which is initially in solid phase. As the material heated, the temperature is increasing and at certain time when it reaches its melting point, the part of solid region transforms to liquid phase. The pump is functioned to circulate fluid from evacuated tube solar collector to PCM storage and back again to absorb heat from solar collector. When the heat from sunrise has reached maximum (peak day), the pump is stopped and letting out the heat which was in the storage to spread out. During this energy storage, phase change materials can store both sensible and latent heat. When the cooking is needed, the heat energy of PCM is delivered to cooking vessel and ready for cooking food.

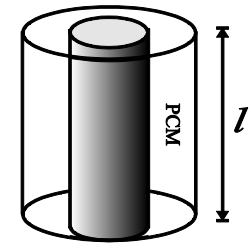

(a)

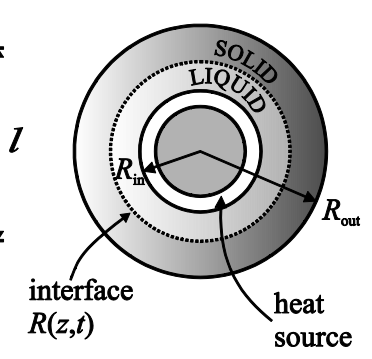

(b)
Fig. 2 (a) PCM storage configuration. (b) Sectional view of the PCM with interface separated solid and liquid region.

Mathematical model of solar cooker system includes heat transfer in PCM, fluid, and cooking vessel. Let assume the PCM storage has inner radius $R_{\text {in, outer }}$ radius $R_{\text {out, }}$ and height $l$, as illustrated in Fig. 2(a) and Fig. 2(b). Thermal conductivity, specific heat, and density of a material are denoted by $k, c$, and $\rho$ respectively. Moreover, $\alpha=k /(\rho c)$ denotes the thermal diffusivity of a material. The domain of PCM storage is partitioned into three regions: 1 ) cooking vessel: $0 \leq z \leq$ $l, 0 \leq r<R_{0}$; 2) HTF: $0 \leq z \leq l, R_{0} \leq \mathrm{r} \leq R_{\mathrm{in}}$, and 3) PCM: $0 \leq$ $z \leq l, R_{\text {in }}<r \leq R_{\text {out. }}$

Heat transfer fluid which passed along inner wall of PCM storage is assumed only depending on axial direction due to high velocity of fluid. Suppose $T^{f}(z, t)$ denotes temperature of HTF at $z \in R$ and time $t$. Let $v$ and $h$ represent velocity and heat transfer coefficient of fluid respectively. Heat equation of fluid flow in hollow cylinder PCM can be written as (Gong \& Mujumdar 1996)

$$
\frac{\partial T^{f}}{\partial t}+v \frac{\partial T^{f}}{\partial z}=\frac{2 h}{\rho_{f} c_{f} R_{\mathrm{in}}}\left(T^{\mathrm{surf}}-T^{f}\right)+\alpha_{f} \frac{\partial^{2} T^{f}}{\partial z^{2}},
$$

where $T^{\operatorname{surf}}(z, t)$ is temperature of PCM at $r=R_{\text {in }}$ and superscript $f$ stands for fluid.

Heat transfer in phase change material can be divided into solid and liquid region, separated by sharp interface which is a function of time. Let $R(z, t)$ denotes the interface location at position $z$ and time $t$, as described in Fig. 2(b). Therefore, $R_{\text {in }} \leq r<R(z, t)$ and $R(z, t)$ $<\mathrm{r} \leq R_{\text {out }}$ are liquid and solid region respectively. It is assumed that heat transfer inside PCM is axially symmetry. Heat conduction equations in liquid and solid region are given by (Agyenim et al. 2010)

$$
\begin{aligned}
& \frac{\partial T^{P}}{\partial t}=\frac{\alpha_{L}}{r} \frac{\partial}{\partial r}\left(r \frac{\partial T^{P}}{\partial r}\right)+\alpha_{L} \frac{\partial^{2} T^{P}}{\partial z^{2}} \quad \text { (liquid), } \\
& \frac{\partial T^{P}}{\partial t}=\frac{\alpha_{S}}{r} \frac{\partial}{\partial r}\left(r \frac{\partial T^{P}}{\partial r}\right)+\alpha_{S} \frac{\partial^{2} T^{P}}{\partial z^{2}} \quad \text { (solid), }
\end{aligned}
$$

where $T^{P}(r, z, t)$ denotes temperature of phase change material at $(r, z) \in R^{2}$ and time $t$. Subscript $L$ and $S$ represent liquid and solid phase respectively.

Let $T_{\mathrm{m}}$ denotes melting point of the phase change material. Temperature at interface location is then expressed as

$$
T^{P}(r, z, t)=T_{m}, \quad r=R(z, t), 0 \leq z \leq l .
$$

According to conservation of energy in liquid and solid phase, the heat conduction equations of (2) and (3) must be satisfied at the interface location. Therefore, the condition at the interface can be mathematically written as

$$
\rho L \frac{\partial R}{\partial t}=-k_{L} \frac{\partial T^{P}}{\partial r}\left(R^{-}, z, t\right)+k_{S} \frac{\partial T^{P}}{\partial r}\left(R^{+}, z, t\right)
$$


where $L$ denotes latent heat of fusion of the phase change material and $\partial T^{\mathrm{P}} / \partial r\left(R^{\mp}, z, t\right)$ denotes the values of $\partial T^{\mathrm{P}} / \partial r(R, z, t)$ as $r \rightarrow R$ from left and right respectively. Equation (5) expresses conservation of energy across the interface $r=R(z, t)$ in cylindrical domain and well known as the Stefan condition.

Heat transfer of a load in cooking vessel is simply formulated as

$$
\left(T^{\mathrm{ves}}-T^{\mathrm{load}}\right)=\gamma_{\mathrm{load}} \frac{d T^{\mathrm{load}}}{d t},
$$

where $\gamma_{\text {load }}$ is a constant proportionality. Moreover, Tload and $T^{\text {ves }}$ represent average temperature of load and cooking vessel respectively. Here, the influenced temperature from surrounding environment is neglected.

Let $T_{0}<T_{\mathrm{m}}$ denotes the initial temperature of phase change material. Then, the initial conditions of (1) - (5) can be expressed as

$$
T(r, z, 0)=T_{0}, \quad R(z, 0)=R_{\text {in }} .
$$

Let $T_{\text {in }}(t)$ be temperature of HTF when entering PCM storage as function of time $t$. Hence, boundary condition at this location is given by

$$
T^{F}(r, 0, t)=T_{\text {in }}, \quad R_{0} \leq r \leq R_{\text {in }} .
$$

When HTF is entering inner wall of cylindrical PCM, the amount of heat is absorbed by the PCM. The boundary condition of inner wall of cylindrical PCM can be simply presented as

$$
k_{L} \frac{\partial T^{P}}{\partial r}=h\left(T^{\text {surf }}-T^{F}\right), r=R_{\text {in }}, \quad 0 \leq z \leq l
$$

Further, the other boundaries are insulated so that there is no heat flux across these areas. The boundary conditions are given by

$$
\begin{aligned}
& \frac{\partial T^{P}}{\partial z}(r, 0, t)=0, \quad R_{\text {in }} \leq r \leq R_{\text {out }}, \\
& \frac{\partial T^{P}}{\partial z}(r, l, t)=0, \quad R_{\text {in }} \leq r \leq R_{\text {out }}, \\
& k_{S} \frac{\partial T^{P}}{\partial z}\left(R_{\text {out }}, z, t\right)=0, \quad 0 \leq z \leq l .
\end{aligned}
$$

The thermal performance of solar cooker is determined by calculating total heat that can be stored in PCM and HTF as well as temperature history at some selected points. Heat energy stored in the PCM storage encompasses sensible and latent heat. The stored energy at time $t$ is given by

$$
\begin{aligned}
E_{P C M}(t) & =\int_{0}^{l} \int_{\mathrm{R}_{\mathrm{in}}}^{R(z, t)}\left\{\rho c_{S}\left[T_{m}-T_{\mathrm{ref}}\right]\right\} 2 \pi r d r d z \\
+ & \int_{0}^{l} \int_{R_{\mathrm{in}}}^{R(z, t)}\left\{\rho c_{L}\left[T(r, z, t)-T_{m}\right]+\rho L\right\} 2 \pi r d r d z \\
+ & \int_{0}^{l} \int_{R(z, t)}^{R_{\text {out }}} \rho c_{S}\left[T(r, z, t)-T_{r e f}\right] 2 \pi r d r d z .
\end{aligned}
$$

Moreover, the amount of sensible heat in HTF at time $t$ can be formulated as

$$
E_{H T F}(t)=\int_{0}^{l} \int_{0}^{R_{\mathrm{in}}} \rho_{f} c_{f}\left[T(r, z, t)-T_{r e f}\right] 2 \pi r d r d z .
$$

where $T_{\text {ref }}$ is the reference temperature. Here, the initial temperature $T_{0}$ is considered as $T_{\text {ref. }}$ Numerical approximation of integral is used to solve (13) and (14).

\section{Numerical Solution}

In this section, numerical solution to solve the phase change problem using Godunov method is presented via enthalpy formulation. More discussion about enthalpy method for the phase change problem can be found in the literatures (Voller \& Cross 1981; Voller \& Shadabi 1984; Esen \& Kutluay 2004). The stability condition of the numerical scheme is also discussed.

\subsection{Godunov scheme}

The predicament in solving phase change problem formulated in (1) - (12) is the presence of moving solidliquid interface of (2) and (3). In this case, heat conduction equations both in liquid and solid phase must be solved with the moving boundary is unknown. The such problem is known as a Stefan problem (Alexiades \& Solomon 1981). A method to solve the problem is by reconstructing heat conduction equations in each phase into single enthalpy or energy equation. By considering the enthalpy form, the moving boundary are excluded in the computation but it is as part of the solution. Suppose $E(r, z, t)$ denotes enthalpy per unit volume at $(r, z) \in R^{2}$ and time $t$. The enthalpy $E(r, z, t)$ can be expressed as sum of sensible and latent:

$$
E(r, z, t)= \begin{cases}\rho c_{s}\left[T(r, z, t)-T_{m}\right], & T(r, z, t)<T_{m} \\ \rho c_{L}\left[T(r, z, t)-T_{m}\right]+\rho L, & T(r, z, t)>T_{m}\end{cases}
$$

By using (15), equation (2) and (3) can be written into single enthalpy form 


$$
\frac{\partial E}{\partial t}=\frac{k}{r} \frac{\partial}{\partial r}\left(r \frac{\partial T^{P}}{\partial r}\right)+k \frac{\partial^{2} T^{P}}{\partial z^{2}}, \quad R_{\text {in }} \leq r \leq R_{\text {out }},
$$

where $k$ depends on the phase.

Numerical solution of (16) is obtained by implementing Godunov method which is based on finite volume discretization. Let the domain $\left[R_{\text {in }}, R_{\text {out }}\right]$ and $[0, l]$ be divided into $M_{1}$ and $\mathrm{M}_{2}$ subintervals respectively. The length of each subinterval is $\Delta r=\left(R_{\text {out }}-R_{\text {in }}\right) / M_{1}$ for radial direction and $\Delta z=l / M_{2}$ for axial direction. Suppose

$$
\begin{array}{ll}
r_{i-1 / 2}=R_{\mathrm{in}}+(i-1) \Delta r, & i=1,2, \cdots, M_{1} \quad \text { and } \\
z_{j-1 / 2}=(j-1) \Delta z, & j=1,2, \cdots, M_{2}
\end{array}
$$

are points that divided the two-dimensional cylindrical domain where $r_{\mathrm{i}}$ is a midpoint between $r_{\mathrm{i}-1 / 2}$ and $r_{\mathrm{i}+1 / 2}$.

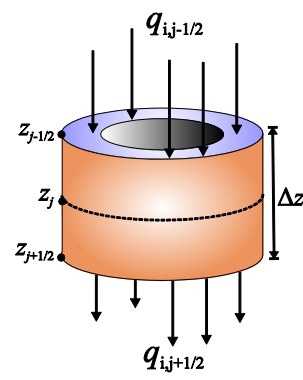

(a)

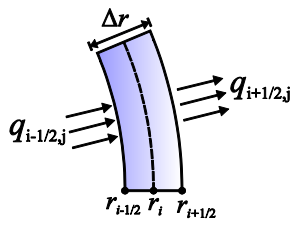

(b)
Fig. 3 Control volume $V_{\text {ij }}$ in two-dimensional cylindrical domain: (a) axial direction; (b) radial direction.

Let $V_{\mathrm{i}, \mathrm{j}}=\left[r_{\mathrm{i}-1 / 2}, r_{\mathrm{i}+1 / 2}\right] \times\left[\mathrm{z}_{\mathrm{j}-1 / 2}, z_{\mathrm{j}+1 / 2}\right]$ is referred as to control volume. As displayed in Fig. 3, volume of $V_{\mathrm{i}, \mathrm{j}}$ can be calculated by

$$
\Delta V_{i, j}=\left(\pi r_{i+1 / 2}^{2}-\pi r_{i-1 / 2}^{2}\right) \Delta z
$$

Since $r_{\mathrm{i}-1 / 2}=r_{\mathrm{i}}-\Delta r / 2$ and $r_{\mathrm{i}+1 / 2}=r_{\mathrm{i}}+\Delta r / 2$, then (19) can be written as

$$
\Delta V_{i, j}=2 \pi r_{i} \Delta r \Delta z
$$

Energy conservation equation in integral form is used when implementing Godunov method instead of using differential form expressed in (16) since it can resolve discontinuity at the solid-liquid interface. The energy conservation in control volume $V_{\mathrm{i}, \mathrm{j}}$ can be easily obtained as (Tarwidi \& Pudjaprasetya 2013)

$$
\int_{V_{i, j}}[E(r, z, t+\Delta t)-E(r, z, t)] d A=\int_{t}^{t+\Delta t} \int_{\partial V_{i, j}}-\mathbf{q} \cdot \mathbf{n} d S d t
$$

where $-\mathbf{q} \cdot \mathbf{n}$ stands for heat flux across $\partial V_{\mathrm{i}, \mathrm{j}}$ and $\mathbf{n}$ denotes the outgoing unit normal to $\partial V_{\mathrm{i}, \mathrm{j}}$. Here, $\mathbf{q}$ is given by Fourier's Law:

$$
\mathbf{q}=-k \nabla T \text {. }
$$

By considering the Mean Value Theorem

$$
\frac{1}{\Delta V_{i, j}} \int_{V_{i, j}} E(r, z, t) d A \approx E\left(r_{i}, z_{j}, t\right)
$$

then (21) can be written as

$$
\begin{aligned}
& {\left[E\left(r_{i}, z_{j}, t+\Delta t\right)-E\left(r_{i}, z_{j}, t\right)\right] \Delta V_{i, j}=} \\
& \int_{t}^{t+\Delta t}\left[q\left(r_{i-1 / 2}, z_{j}, t\right) A_{i-1 / 2, j}-q\left(r_{i+1 / 2}, z_{j}, t\right) A_{i+1 / 2, j}\right] d t+ \\
& \int_{t}^{t+\Delta t}\left[q\left(r_{i}, z_{j-1 / 2}, t\right) A_{i, j-1 / 2}-q\left(r_{i}, z_{j+1 / 2}, t\right) A_{i, j+1 / 2}\right] d t,
\end{aligned}
$$

where $A_{\mathrm{i} \mp 1 / 2, \mathrm{j}}$ and $A_{\mathrm{i}, \mathrm{j} \mp 1 / 2}$ are area that passed through by

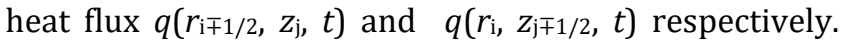
From Fig. 3, these areas are given by

$$
\begin{aligned}
& A_{i \mp 1 / 2, j}=2 \pi r_{i \mp 1 / 2, j} \Delta r, \\
& A_{i, j \mp 1 / 2}=\pi r_{i+1 / 2}^{2}-\pi r_{i-1 / 2}^{2}=2 \pi r_{i} \Delta r,
\end{aligned}
$$

Suppose $E_{\mathrm{i}, j^{\mathrm{n}}}=E\left(r_{\mathrm{i}}, z_{\mathrm{j}}, t^{\mathrm{n}}\right), T_{\mathrm{i}, \mathrm{j}}^{\mathrm{n}}=T\left(r_{\mathrm{i}}, Z_{\mathrm{j}}, t^{\mathrm{n}}\right)$, and $q_{\mathrm{i}, \mathrm{j}^{\mathrm{n}}}=$ $q\left(r_{\mathrm{i}}, Z_{\mathrm{j}}, t^{\mathrm{n}}\right)$ where $t^{\mathrm{n}}=n \Delta t, n \in \mathbf{N}$. The discrete solution in explicit scheme of energy conservation (21) can be written as

$$
\begin{aligned}
E_{i, j}^{n+1}=E_{i, j}^{n} & +\frac{\Delta t}{r_{i, j} \Delta r}\left[q_{i-1 / 2, j}^{n} r_{i-1 / 2, j}-q_{i+1 / 2, j}^{n} r_{i+1 / 2, j}\right] \\
& +\frac{\Delta t}{r_{i, j} \Delta z}\left[q_{i, j-1 / 2}^{n}-q_{i, j+1 / 2}^{n}\right],
\end{aligned}
$$

where

$$
\begin{aligned}
& q_{i-1 / 2, j}^{n}=-\frac{T_{i, j}^{n}-T_{i-1, j}^{n}}{\kappa_{i-1 / 2, j}}, \quad \kappa_{i-1 / 2, j}=\frac{\Delta r}{2}\left(\frac{1}{k_{i-1, j}}+\frac{1}{k_{i, j}}\right), \\
& q_{i, j-1 / 2}^{n}=-\frac{T_{i, j}^{n}-T_{i, j-1}^{n}}{\kappa_{i, j-1 / 2}}, \quad \kappa_{i, j-1 / 2}=\frac{\Delta z}{2}\left(\frac{1}{k_{i, j-1}}+\frac{1}{k_{i, j}}\right) .
\end{aligned}
$$

Temperature at each control volume can be obtained by substituting (27) - (29) to (15) and reformulating it into equation of temperature: 


$$
T_{i, j}^{n+1}=\left\{\begin{array}{l}
T_{m}+\frac{E_{i, j}^{n+1}}{\rho c_{s}}, \quad E_{i, j}^{n+1} \leq 0, \quad \text { (solid) } \\
T_{m}, \quad 0<E_{i, j}^{n+1}<\rho c_{L}, \quad \text { (mushy) } \\
T_{m}+\frac{E_{i, j}^{n+1}-\rho L}{\rho c_{L}}, \quad E_{i, j}^{n+1} \geq \rho c_{L}, \quad \text { (liquid) }
\end{array}\right.
$$

Here, the value of $k_{\mathrm{i}, \mathrm{j}}$ should be updated with $k_{\mathrm{i}, \mathrm{j}}=k_{\mathrm{s}}, k_{\mathrm{i}, \mathrm{j}}$ $=k_{\mathrm{L}}$, and $k_{\mathrm{i}, \mathrm{j}}=\left(k_{\mathrm{L}}+k_{\mathrm{s}}\right) / 2$ for solid, liquid, and mushy region respectively.

\subsection{Boundary condition}

Boundary condition in (9) can be expressed as finite volume discretization:

$$
\frac{T_{0, j}^{n}-T_{1, j}^{n}}{\kappa_{1 / 2, j}}=h\left(T_{0, j}^{n}-T_{j}^{F}\right) \text {, where } \kappa_{1 / 2, j}=\frac{\Delta r}{2 k_{L}} .
$$

Rewrite (31) to obtain

$$
T_{0, j}^{n}=\frac{T_{1, j}^{n}+h \kappa_{1 / 2, j} T_{j}^{F}}{1+h \kappa_{1 / 2, j}} .
$$

Equation (10) - (12) can also be expressed in discrete form by substituting $h=0$ into (31).

\subsection{Stability condition}

It can be seen that the numerical solution (27) is conditionally stable because explicit scheme is adopted. The stability condition can be briefly obtained as follows. It is assumed that only plain heat conduction considered or in other words there is no latent heat of fusion involved. Hence, (15) can be written as

$$
E_{i, j}^{n}=\rho\left[T_{i, j}^{n}-T_{m}\right] .
$$

As consequence, $k=k_{\mathrm{L}}=k_{\mathrm{s}}$ and $\alpha=\alpha_{\mathrm{L}}=\alpha_{\text {s. }}$. Substituting (28), (29), and (33) into (27) leads to

$$
\begin{aligned}
T_{i, j}^{n+1}=T_{i, j}^{n} & +\frac{\alpha \Delta t}{(\Delta r)^{2}}\left[\frac{r_{i-1 / 2}}{r_{i}} T_{i-1, j}^{n}-\frac{r_{i-1 / 2}+r_{i+1 / 2}}{r_{i}} T_{i, j}^{n}+\frac{r_{i+1 / 2}}{r_{i}} T_{i+1, j}^{n}\right] \\
& +\frac{\alpha \Delta t}{(\Delta z)^{2}}\left[T_{i, j-1}^{n}-2 T_{i, j}^{n}+T_{i, j+1}^{n}\right] .
\end{aligned}
$$

Without loss of generality, suppose $\Delta r=\Delta z$, so that $M_{1}=$ $M_{2}=M$. Rearrange (34) to yield

$$
T_{i, j}^{n+1}=\frac{\alpha \Delta t}{(\Delta r)^{2}} \frac{r_{i-1 / 2}}{r_{i}} T_{i-1, j}^{n}+\left[1-\frac{\alpha \Delta t}{(\Delta r)^{2}}\left(\frac{r_{i-1 / 2}+r_{i+1 / 2}}{r_{i}}-2\right)\right] T_{i, j}^{n}
$$

$$
+\frac{\alpha \Delta t}{(\Delta r)^{2}} \frac{r_{i+1 / 2}}{r_{i}} T_{i+1, j}^{n}+\frac{\alpha \Delta t}{(\Delta r)^{2}} T_{i, j-1}^{n}+\frac{\alpha \Delta t}{(\Delta r)^{2}} T_{i, j+1}^{n}
$$

The stability condition of (35) according to CourantFriedrichs-Lewy (CFL) condition is

$$
1-\frac{\alpha \Delta t}{(\Delta r)^{2}}\left(\frac{r_{i-1 / 2}+r_{i+1 / 2}-2 r_{i}}{r_{i}}\right) \geq 0, \quad i=2, \cdots, M-1 .
$$

Equation (36) can be rewritten as

$$
\frac{\alpha \Delta t}{(\Delta r)^{2}}\left(\frac{r_{i-1 / 2}+r_{i+1 / 2}-2 r_{i}}{r_{i}}\right) \leq 1, \quad i=2, \cdots, M-1
$$

The computational time step $\Delta t$ must satisfy the stability criterion of (37). However, it will be an expensive computation since the stability condition must be checked for all internal nodes. Therefore, it requires to determine maximum permissible time step by taking maximum value of left hand side of (37):

$$
\max _{2 \leq i \leq M-1}\left\{\frac{\alpha \Delta t}{(\Delta r)^{2}}\left(\frac{r_{i-1 / 2}+r_{i+1 / 2}-2 r_{i}}{r_{i}}\right)\right\} \leq 1 .
$$

Equation (38) can also be expressed as

$$
\Delta t \leq \min _{2 \leq i \leq M-1}\left\{\frac{(\Delta r)^{2}}{\alpha}\left(\frac{r_{i}}{r_{i-1 / 2}+r_{i+1 / 2}+2 r_{i}}\right)\right\} .
$$

By using (17), equation (39) becomes

$$
\Delta t \leq \min _{2 \leq i \leq M-1}\left\{\frac{(\Delta r)^{2}}{\alpha}\left(\frac{R_{\mathrm{in}}+(i-1 / 2) \Delta r}{4 R_{\mathrm{in}}+(4 i-2) \Delta r}\right)\right\} .
$$

Then, equation (40) can be simply presented as

$$
\Delta t \leq \frac{(\Delta r)^{2}}{\alpha}\left(\frac{R_{\mathrm{in}}+3 / 2 \Delta r}{4 R_{\mathrm{in}}+4 M \Delta r-6 \Delta r}\right) .
$$

Since $M=\left(R_{\text {out }}-R_{\text {in }}\right) / \Delta r$, then (41) can be simplified to

$$
\Delta t \leq \frac{1}{4} \frac{(\Delta r)^{2}}{\alpha}\left(\frac{R_{\mathrm{in}}}{R_{\text {out }}}\right) .
$$

However, in this study, $\Delta r$ and $\Delta z$ may different and thermal diffusivity of each phase is obviously different so that (42) may be expressed as 


$$
\Delta t \leq \frac{1}{4} \frac{\left(\Delta r_{\min }\right)^{2}}{\alpha_{\max }}\left(\frac{R_{\mathrm{in}}}{R_{\mathrm{out}}}\right),
$$

where $\Delta r_{\min }=\min \{\Delta r, \Delta z\}$ and $\alpha_{\max }=\max \left\{\alpha_{\mathrm{L}}, \alpha_{\mathrm{S}}\right\}$. The maximum permissible time step is given by right hand side of (43). The CFL number for stability condition of the numerical scheme in (34) can then be obtained as

$$
C F L=\frac{\alpha_{\max } \Delta t}{\left(\Delta r_{\text {min }}\right)^{2}}\left(\frac{R_{\text {out }}}{R_{\text {in }}}\right) .
$$

Note that from (43), the CFL number for twodimensional outward melting problem in cylindrical domain must be smaller than or equal to $1 / 4$. It can also be easily obtained that for one-dimensional case, the CFL number must be smaller than or equal to $1 / 2$. Further, the stability condition of Godunov scheme for heat conduction equation in Cartesian domain can be derived by setting $R_{\text {in }}=R_{\text {out }}$ of (43) and (44).

\subsection{Numerical verification}

The Godunov scheme is verified by comparing the numerical solution with the analytical solution. However, the analytical solution can be obtained only for one-dimensional and one-phase melting problem where the axial term is neglected. In this study, the analytical solution is approached by quasistationary approximation. The approximation is obtained by replacing the heat conduction equations with steadystate equation, $r \partial T / \partial r=0$, while it allows the phase change interface changing with time. As a result, the initial conditions could not be fulfilled and only applied to one-phase Stefan problem. In physical meaning, the quasistationary approximation only considers latent heat of fusion so the sensible heat is negligible. As consequence, the interface location (melt front) of the quasistationary solution will overestimate the actual one (Alexiades \& Solomon 1981).

The quasistationary approximation will be applied to one-phase outward melting problem of a hollow cylinder. Suppose that there is a very long hollow cylinder with inner radius $R_{\text {in }}$ and outer radius $R_{\text {out. }}$ The cylinder initially contains phase change material in solid state with temperature at its melting point $T_{\mathrm{m}}$. At inner surface $r=R_{\text {in }}$, it is imposed uniform temperature $T_{\mathrm{L}}>$ $T_{\mathrm{m}}$. As a result, the PCM will melt with axially symmetric heat transfer and melt front $R(t)$ will move from $r=R_{\text {in }}$ toward outer radius. This melting will form liquid region: $r=R_{\text {in }} \leq r<R(t)$ and solid region: $R(t)<r \leq R_{\text {out. }}$ The described problem can be formulated as

$$
\begin{gathered}
\frac{\partial T}{\partial t}=\frac{\alpha_{L}}{r} \frac{\partial}{\partial r}\left(r \frac{\partial T}{\partial r}\right), R_{\mathrm{in}}<r<R(t), t>0 \\
T(R(t), t)=T_{m}, \quad t>0
\end{gathered}
$$

$$
\begin{gathered}
\rho L \frac{\partial R(t)}{\partial t}=-k_{L} \frac{\partial T}{\partial r}\left(R(t)^{-}, t\right), \quad t>0 \\
R(0)=R_{\mathrm{in}}, \\
T\left(R_{\mathrm{in}}, t\right)=T_{L}, \quad t>0 .
\end{gathered}
$$

The quastationary approximation can be obtained by replacing heat conduction equation (45) with steady state equation $r \partial T / \partial r=0$ then integrate it. The constants which appear from integration can be obtained by substituting (46)-(49) into integration result. The analytical solution for this case is given by

$$
T^{\mathrm{qs}}(r, t)=T_{m}+\left[T_{L}-T_{m}\right] \frac{\ln \left(\frac{r}{R^{\mathrm{qs}}(t)}\right)}{\ln \left(\frac{R_{\mathrm{in}}}{R^{\mathrm{qs}}(t)}\right)},
$$

where $R^{\mathrm{qs}}$ is quasistationary solution of melt front. $R^{\mathrm{qs}}$ is obtained by solving transcendental equation

$$
2 R^{\mathrm{qs}}(t)^{2} \ln \left(\frac{R^{\mathrm{qs}}(t)}{R_{\mathrm{in}}}\right)=R^{\mathrm{qs}}(t)^{2}-R_{\mathrm{in}}^{2}+\frac{4 k_{L}}{\rho L}\left(T_{L}-T_{m}\right) t
$$

Equation (51) can be solved easily using the NewtonRaphson method.

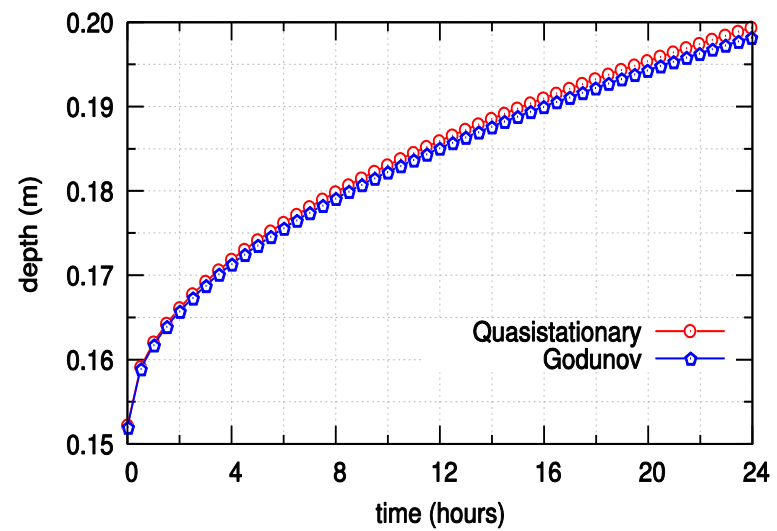

Fig. 4 Quasistationary and Godunov solution for melt front with $\Delta r=$ $0.0010703125 \mathrm{~m}$ and $\Delta t=4.9474$ seconds for $t_{\max }=24$ hours.

In this numerical verification, PCM erythritol is used in the computation of melt front and temperature profile. The thermophysical properties of erythritol are $\alpha_{\mathrm{L}}=7.98 \cdot 10^{-8} \mathrm{~m}^{2} / \mathrm{s}$ and $T_{\mathrm{m}}=118^{\circ} \mathrm{C}$. The imposed temperature at $r=R_{\text {in }}$ is $T_{\mathrm{L}}=140^{\circ} \mathrm{C}$. Furthermore, the inner and outer radius of PCM are $R_{\text {in }}=0.152 \mathrm{~m}$ and $R_{\text {out }}$ $=0.2205 \mathrm{~m}$, respectively. Then, the quasistationary solution of temperature profile in (50) and melt front in (51) can be easily calculated.

One-dimensional Godunov method for solving (45)(49) is then compared with the quasistationary 
Citation: Tarwidi, D., Murdiansyah, D.T, Ginanja, N. (2016) Performance Evaluation of Various Phase Change Materials for Thermal Energy Storage of A Solar Cooker via Numerical Simulation. Int. Journal of Renewable Energy Development, 5(3), 199-210, doi: 10.14710/ijred.5.3.199-210

$\mathrm{P}$ a g e $\mid 206$

approximation. In this case, the time-dependent onedimensional Godunov scheme is given by (27) but without last term of the right hand side (axial term). The numerical solution of temperature profile is calculated by (30). Moreover, the numerical approximation of $R(t)$ can be calculated by

$$
R^{\mathrm{num}}=R_{\mathrm{in}}+r_{i-1 / 2}+\lambda \Delta r
$$

where $\lambda$ is liquid fraction. More comprehensive review of liquid fraction can be seen in (Alexiades \& Solomon 1981; Tarwidi \& Pudjaprasetya 2013).

Fig. 4 depicts melt front of quasistationary and numerical approach. As predicted, the quasistationary solution of melt front overestimates the numerical solution. From the figure, it can be seen that the difference of melt front between quasistationary and Godunov solution becomes larger as increasing of time. Absolute error of melt front for various $\Delta r$ within 24 hours is displayed by Fig. 5 . It can also be observed that the resulting error for each $\Delta r$ within 24 hours experiences oscillation. However, for $\Delta r=0.002140625$ and $\Delta r=0.0010703125$, the resulting error is quite small and the oscillation is also very small. In general, the smaller $\Delta r$ the smaller oscillation produced. Regarding to the oscillation, error of melt front is highly influenced by the time progression. Moreover, for the same $\Delta r$, the error of melt front tends to grow by increasing of time.

Absolute and relative error of melt front for various $\Delta r$ at $t=24$ hours is summarized in Table 1 . In this computation, the CFL number for the stable calculation is 0.5 . The table also shows the appropriate $\Delta t$ which satisfies the CFL number. It can be seen from the table that when $\Delta r$ is halved, the resulting error does not change significantly except for $\Delta r=0.0085625$ and $\Delta r=$ 0.00428125 . However, in general, the error is getting smaller as decreasing of $\Delta r$ except for $\Delta r=$ 0.002140625 , the error is raising up. From Table 1 , it can also be seen that for all $\Delta r$, the accuracy of the Godunov scheme for approximating the melt front is more than $99 \%$.

Table 1

Absolute and relative error of melt front with CFL number 0.5 at $t=24$ hours.

\begin{tabular}{crcl|}
\hline $\boldsymbol{\Delta} \boldsymbol{r}$ (meters) & $\begin{array}{c}\boldsymbol{\Delta} \boldsymbol{t} \\
\text { (seconds) }\end{array}$ & $\begin{array}{c}\left|\boldsymbol{R}^{\mathbf{q s}}-\boldsymbol{R}^{\text {num }}\right| \\
\text { at } \boldsymbol{t}=\mathbf{2 4} \text { hours }\end{array}$ & $\begin{array}{l}\text { \% } \\
\text { error }\end{array}$ \\
\hline 0.017125000000 & 1266.5413 & 0.001955 & $0.981 \%$ \\
0.008562500000 & 316.6353 & 0.001476 & $0.740 \%$ \\
0.004281250000 & 79.1588 & 0.001171 & $0.587 \%$ \\
0.002140625000 & 19.7897 & 0.001187 & $0.595 \%$ \\
0.001070312500 & 4.9474 & 0.001178 & $0.591 \%$ \\
0.000535156250 & 1.2369 & 0.001173 & $0.588 \%$ \\
0.000267578125 & 0.3092 & 0.001170 & $0.587 \%$ \\
\hline
\end{tabular}

Temperature profile of the outward melting of erythritol at $t=3, t=6, t=12$, and $t=24$ hours with $\Delta \mathrm{r}=$ $0.0010703125 \mathrm{~m}$ and $\Delta \mathrm{t}=4.9474$ seconds is shown by Fig. 6.

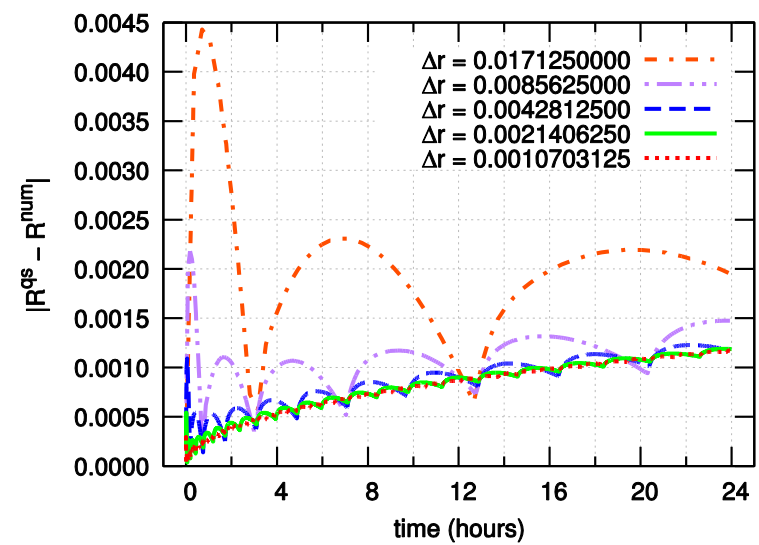

Fig. 5 Absolute error of melt front for various $\Delta r$ and $\mathrm{CFL}=0.5$ from $\mathrm{t}$ $=0$ to $\mathrm{t}=24$ hours.

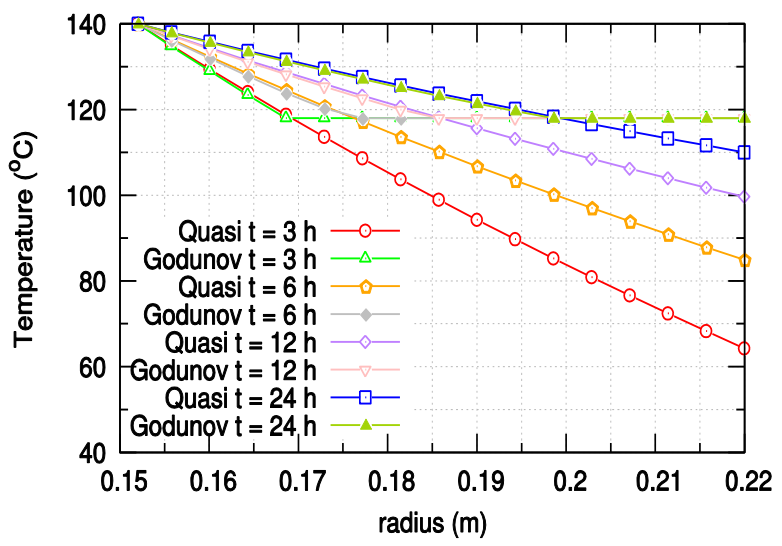

Fig. 6 Quasistationary and Godunov solution for temperature profile with $\Delta r=0.0010703125 \mathrm{~m}, \Delta t=4.9474$ seconds, and CFL $=0.5$ for $t$ $=3, t=6, t=12$, and $t=24$ hours.

It can be observed that the numerical solution of temperature is getting closer to the quasistationary approximation as increasing of time. The numerical results suggest that the Godunov scheme confirms the analytical solution.

\section{Simulation Setup}

Simulation setup to assess thermal performance of phase change materials in the solar cooker can be described as follows. At 07:00, the evacuated solar collector starts to collect solar heat energy from sunshine. At the same time, the pump is turned on to circulate heat transfer fluid from solar collector to PCM storage. It is assumed that there is no heat loss during circulation of the fluid. Some PCMs namely erythritol $\left(\mathrm{C}_{4} \mathrm{H}_{10} \mathrm{O}_{4}\right)$, magnesium nitrate hexahydrate $\left(\mathrm{Mg}\left(\mathrm{NO}_{3}\right)_{2} \cdot 6 \mathrm{H}_{2} \mathrm{O}\right)$, RT100, magnesium chloride hexahydrate $\left(\mathrm{MgCl}_{2} \cdot 6 \mathrm{H}_{2} \mathrm{O}\right)$, and paraffin are selected to be evaluated their thermal performance. Thermophysical properties of the PCMs are summarized in Table 2 while thermophysical properties of heat transfer fluid are listed in Table 3. Further, initial 
temperature of the whole PCM region is considered $20^{\circ} \mathrm{C}$.

It is assumed that heat absorbed by HTF in evacuated tube solar collector from 7:00 to 17:00 is given by Fig. 7. Hence, the inlet temperature $T_{\text {in }}(t)$ which is expressed in (8) is simply shown by Fig. 7. The figure is obtained by considering experimental results from some literatures but with idealization. The experimental results of variation of temperatures in evacuated tube solar collector can be found in the literatures (Sharma et al. 2005; Peng \& Chen 2009; Singh et al. 2015).

Pump to circulate HTF is turned off at 12:30 because the solar intensity has reached the maximum value between 12:00 and 12:30. As a result, heat source for thermal storage only comes from the hot fluid which was in PCM storage. For the simulation, the solar cooker with PCM is used to cook a load of $10 \mathrm{~kg}$ of water, as experimentally conducted by Sharma et al. (2005). At 17:00, the loaded water is put into cooking vessel with the initial temperature is supposed $30^{\circ} \mathrm{C}$. From this time, the heat from the PCM storage is delivered to the loaded water until 21:00.

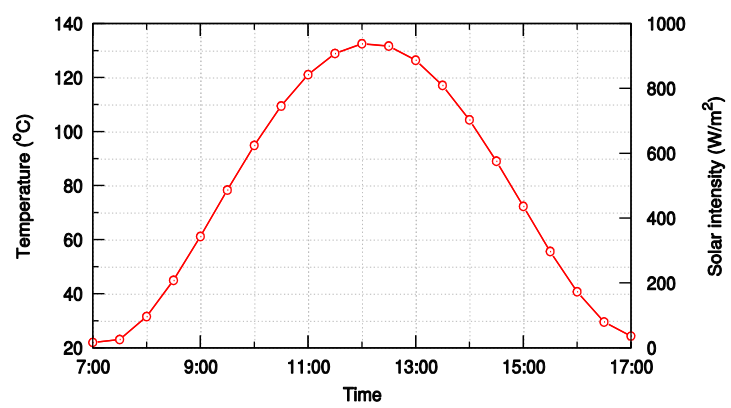

Fig. 7 Heat absorbed by HTF in evacuated tube solar collector from 7:00 to $17: 00$.

Table 2

Thermophysical of the selected PCMs.

\begin{tabular}{|c|c|c|c|c|c|}
\hline Properties & ERT & MNH & RT & МСH & PRF \\
\hline $\begin{array}{l}\text { Density }\left(\mathrm{kg} / \mathrm{m}^{3}\right) \\
\text { Specific heat } \\
\left(\mathrm{kJ} / \mathrm{kg} /{ }^{\circ} \mathrm{C}\right)\end{array}$ & 1480 & 1636 & 940 & 1570 & 837.7 \\
\hline Solid & 1.38 & 1.84 & 1.80 & 2.25 & 3.20 \\
\hline $\begin{array}{l}\text { Liquid } \\
\text { Thermal conductivity } \\
\left(\mathrm{kJ} / \mathrm{m} / \mathrm{s} /{ }^{\circ} \mathrm{C}\right)\end{array}$ & 2.76 & 2.51 & 2.4 & 2.61 & 2.80 \\
\hline $\begin{array}{l}\text { Solid }\left(\times 10^{-3}\right) \\
\text { Liquid }\left(\times 10^{-3}\right)\end{array}$ & $\begin{array}{l}0.733 \\
0.326\end{array}$ & $\begin{array}{l}0.611 \\
0.490\end{array}$ & $\begin{array}{l}0.200 \\
0.200\end{array}$ & $\begin{array}{l}0.704 \\
0.570\end{array}$ & $\begin{array}{l}0.350 \\
0.150\end{array}$ \\
\hline $\begin{array}{l}\text { Melting temperature } \\
\left({ }^{\circ} \mathrm{C}\right)\end{array}$ & 118 & 89 & 99 & 116.7 & 72 \\
\hline $\begin{array}{l}\text { Latent heat of fusion } \\
(\mathrm{kJ} / \mathrm{kg})\end{array}$ & 339.8 & 162.8 & 168 & 168.6 & 224 \\
\hline Stefan number* & 0.18 & 0.79 & 0.59 & 0.36 & 0.85 \\
\hline
\end{tabular}

Source:

ERT = erythritol (Sharma et al. 2005)

MNH = magnesium nitrate hexahydrate (Chen et al. 2008)

RT = RT100 (Sharma et al. 2009)

MCH = magnesium chloride hexahydrate (Choi \& Kim 1992)

PRF $=$ Paraffin (Peng \& Chen 2009)

*Stefan number $=c_{L}\left(T_{L^{-}} T_{m}\right) / L$, where $T_{L}=140^{\circ} \mathrm{C}$
Table 3

Other parameters of the simulation.

\begin{tabular}{|lcl|}
\hline Parameter & Value* & Unit \\
\hline Heat transfer fluid (HTF) & & \\
Density & 1000 & $\mathrm{~kg} / \mathrm{m}^{3}$ \\
Specific heat & 4.2 & $\mathrm{~kJ} / \mathrm{kg} /{ }^{\circ} \mathrm{C}$ \\
Thermal conductivity & $0.6 \cdot 10^{-3}$ & $\mathrm{~kJ} / \mathrm{m} / \mathrm{h} /{ }^{\circ} \mathrm{C}$ \\
Average velocity inside annulus & 0.5 & $\mathrm{~m} / \mathrm{s}$ \\
PCM storage & & \\
Inner radius & 0.1520 & $\mathrm{~m}$ \\
Outer radius & 0.2205 & $\mathrm{~m}$ \\
$\quad$ Height & 0.3 & $\mathrm{~m}$ \\
Convective heat transfer coefficient & 2.44 & $\mathrm{~kJ} / \mathrm{m}^{2} / \mathrm{s} /{ }^{\circ} \mathrm{C}$ \\
\hline
\end{tabular}

Source: *(Esen \& Ayhan 1996; Gong \& Mujumdar 1997)

The cylindrical PCM storage has size $0.3 \mathrm{~m}$ of height, $0.152 \mathrm{~m}$ of inner radius, and $0.2205 \mathrm{~m}$ of outer radius. For the space discretization, it is used $\Delta r=$ 0.0010703125 and $\Delta z=0.0046875$. Since the CFL number depends on thermal diffusivity of $\alpha_{\mathrm{L}}$ and $\alpha_{S}$ then the stability condition for $\Delta t$ will be different for each PCM. However, it is required to compare the simulation results of each PCM in the same time step. As consequence, a fixed time step which satisfies stability condition of all PCMs must be chosen. The fixed time step must be smaller than or equal to the smallest value of the maximum permissible time step of all PCMs. In this numerical simulation, the fixed time step $\Delta t=0.01$ is used. Finally, the temperature distribution in each time step is calculated by (27) and (30).

\section{Numerical Results and Discussion}

Numerical results of phase change materials simulation are discussed in this section. Thermal performance of solar cooker is evaluated based on stored energy and temperature history of the selected PCMs. At the end of this section, temperature history of the loaded water in cooking vessel with erythritol as heat storage is discussed.

\subsection{Stored energy of the selected PCMs}

Stored energy of the selected PCMs is investigated numerically to obtain the thermal performance. Total heat energy stored in PCM and HTF is calculated by summing up the enthalpy of each control volume, as formulated in (13) and (14). The stored energy of the selected PCMs is depicted by Fig. 8. From this figure, it can be observed that magnesium nitrate hexahydrate and magnesium chloride hexahydrate show higher stored energy than other PCMs. However, for overall simulation time, magnesium chloride hexahydrate has the highest capability to store heat energy. Note that the stored energy is not only stored as latent heat of fusion but also as sensible heat. Moreover, it was found that at $17: 00$, a second before $10 \mathrm{~kg}$ of water is loaded into cooking vessel, magnesium chloride hexahydrate has total energy approximately 8.6 megajoule. Further, at 
21:00, the heat energy of magnesium chloride hexahydrate is decreasing to 7.5 megajoule due to part of the heat is absorbed by the loaded water.

It can also be seen from Fig. 8 that the stored energy of erythritol is relative constant from 12:30 to 17:00. As predicted, the result is affected by the high latent heat of fusion, so that it can absorb large amount of heat. The figure also reveals that stored energy of paraffin overlaps erythritol at 16:00. It can be observed that the entire paraffin material was melted at 16:00 which results the stored energy rate is increasing faster. Moreover, RT100 does not show better thermal performance. The stored energy of RT100 is always lower than other PCMs.

Total heat gained by heat transfer fluid for various phase change materials is displayed by Fig. 9. As can be seen from the figure, the maximum energy of the hot fluid is about 9.8 megajoule and it occurs at 12:00 when the pump is still turned on. Furthermore, at 17:00, when the pump is turned off, the heat energy of HTF is suddenly dropped due to heat absorption by the loaded water. It can be observed that the influence of different of PCMs does not affect significantly to the change of HTF energy.

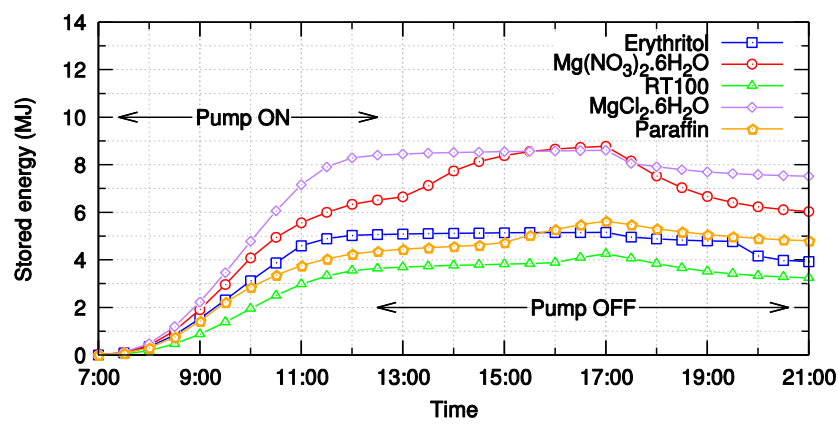

Fig. 8 Stored energy of different PCMs: erythritol, $\mathrm{Mg}\left(\mathrm{NO}_{3}\right)_{2} \cdot 6 \mathrm{H}_{2} \mathrm{O}$ RT100, $\mathrm{MgCl}_{2} \cdot 6 \mathrm{H}_{2} \mathrm{O}$, and paraffin in megajoule (MJ) from 7:00 to 21:00.

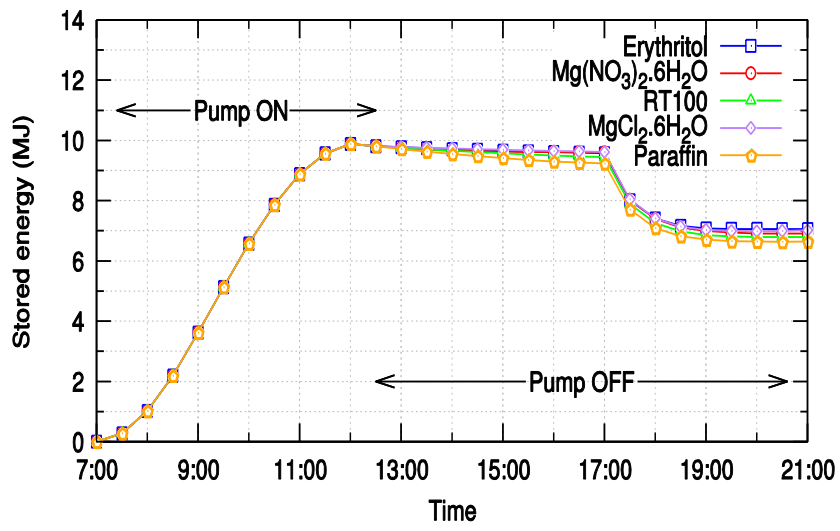

Fig. 9 Stored energy in fluid with different PCMs: erythritol, $\mathrm{Mg}\left(\mathrm{NO}_{3}\right)_{2} \cdot 6 \mathrm{H}_{2} \mathrm{O}$, RT100, $\mathrm{MgCl}_{2} \cdot 6 \mathrm{H}_{2} \mathrm{O}$, and paraffin in megajoule (MJ) from 7:00 to 21:00.

\subsection{Temperature history of the selected PCMs}

Temperature history of point $T_{1}$ whose location illustrated by Fig. 1(c) is presented by Fig. 10. It can be examined that erythritol has the fastest rate of heat transfer during energy storage process and pump on. However, after the pump is turned off and energy storage is still ongoing, heat transfer rate of magnesium chloride hexahydrate is slightly higher than the erythritol with the maximum temperature of erythritol and magnesium chloride hexahydrate is $120^{\circ} \mathrm{C}$ and $122^{\circ} \mathrm{C}$ respectively. The interesting result is shown by temperature history of magnesium nitrate hexahydrate. It has higher temperature history than other PCMs from 14:30 until 17:00 with the maximum temperature during energy storage is approximately $128^{\circ} \mathrm{C}$.

The best thermal performance during energy extraction from 17:00 to $19: 30$ is shown by erythritol. As can be seen in Fig. 10, erythritol has the highest temperature history with temperature range of 115$118^{\circ} \mathrm{C}$. However, magnesium chloride hexahydrate can maintain the temperature in the range of $110-116.7^{\circ} \mathrm{C}$ for more than 4 hours. In contrast, RT00 and paraffin have poor thermal performance.

The influence of latent heat of fusion regarding heat transfer capability can be shown by temperature history of point $T_{2}$ whose position near outer surface of the PCM storage. Fig. 11 depicts temperature history of point $T_{2}$. After the $10 \mathrm{~kg}$ of water is loaded into cooking vessel, the temperature of erythritol is retained in $118^{\circ} \mathrm{C}$ for 2.5 hours. As a result, erythritol is suitable for cooking that need temperature of $118^{\circ} \mathrm{C}$. Further, it is interesting to observe the temperature history of magnesium nitrate hexahydrate during energy extraction. From 17:00 until 18:00, the temperature is decreasing quickly from $128^{\circ} \mathrm{C}$ to $121^{\circ} \mathrm{C}$. As consequence, magnesium nitrate hexahydrate is effective for cooking only for one hour with the temperature range of $121-128^{\circ} \mathrm{C}$. Therefore, if it requires fast cooking time with temperature about $128^{\circ} \mathrm{C}$ then magnesium nitrate hexahydrate can be used as thermal energy storage while if it needs longer cooking time then it can be used erythritol or magnesium chloride hexahydrate.

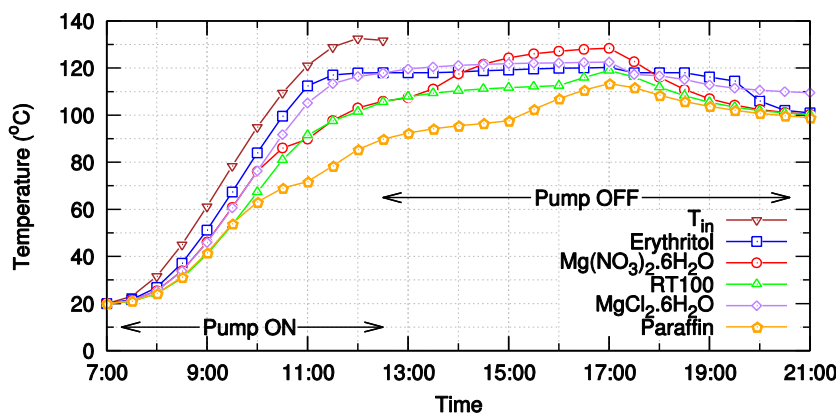

Fig. 10 Temperature history of different PCMs: erythritol, $\operatorname{Mg}\left(\mathrm{NO}_{3}\right)_{2} \cdot 6 \mathrm{H}_{2} \mathrm{O}, \mathrm{RT} 100, \mathrm{MgCl}_{2} \cdot 6 \mathrm{H}_{2} \mathrm{O}$, and paraffin at point $\mathrm{T}_{1}$ from 7:00 to $21: 00$. 


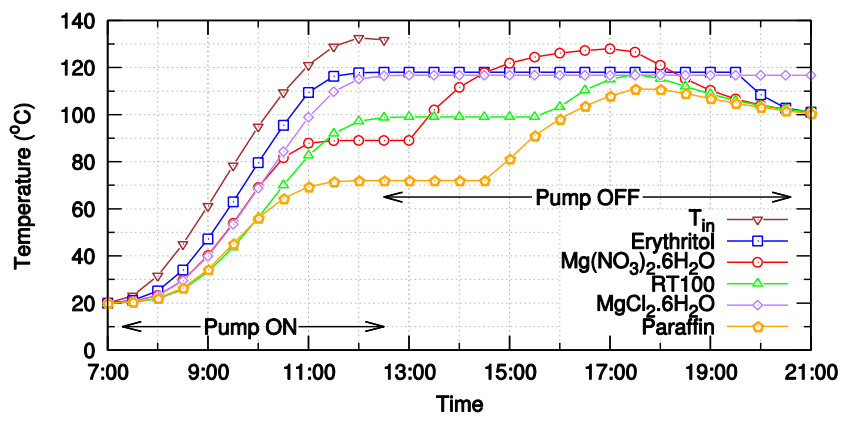

Fig. 11 Temperature history of different PCMs: erythritol, $\mathrm{Mg}\left(\mathrm{NO}_{3}\right)_{2} \cdot 6 \mathrm{H}_{2} \mathrm{O}, \mathrm{RT} 100, \mathrm{MgCl}_{2} \cdot 6 \mathrm{H}_{2} \mathrm{O}$, and paraffin at point $\mathrm{T}_{2}$ from 7:00 to 21:00.

Thermal performance of phase change material can also be evaluated by the Stefan number. Stefan number measures the ratio between sensible and latent heat. The smaller Stefan number of a phase change material the better for storing thermal energy. Stefan numbers during melting process of the selected PCMs are shown by Table 2. It can be seen that all PCMs have Stefan numbers less than one. It means that heat conduction transfer of the PCM is strongly affected by the phase change. In this case, Stefan number of erythritol is smaller than the other PCMs so that it is the most suitable for thermal energy storage compared to other selected PCMs.

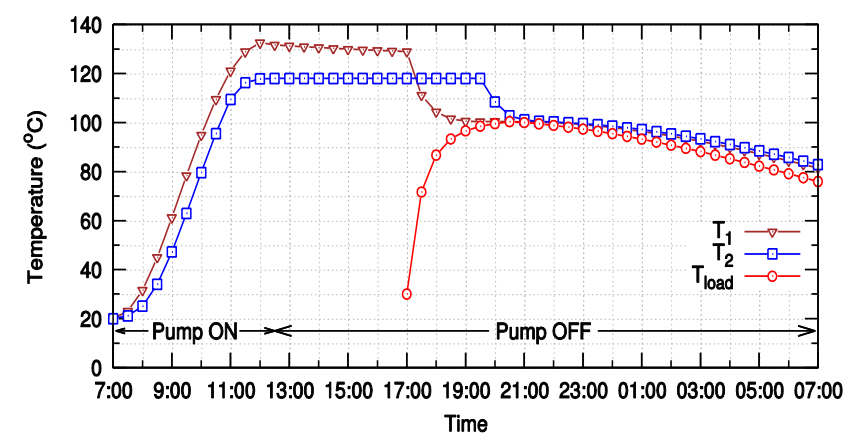

Fig. 12 Temperature history of the loaded water with erythritol as thermal energy storage for 24 hours of the simulation.

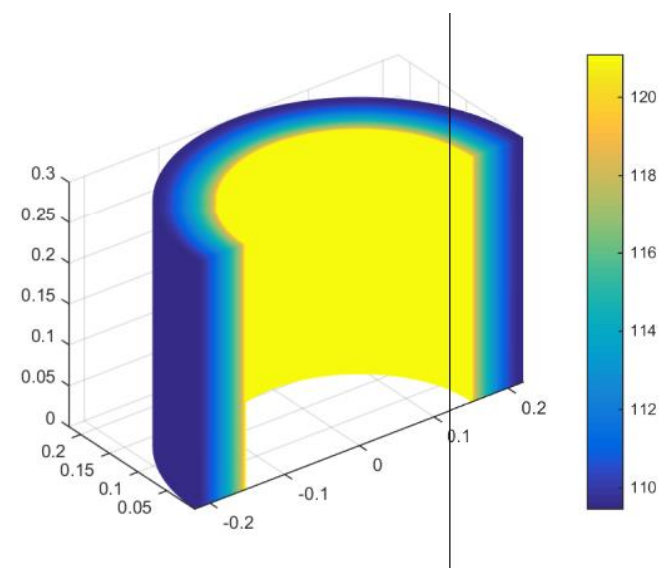

Fig. 13 Three-dimensional temperature distribution of PCM storage using erythritol in a half domain at $\mathrm{t}=5.6$ hours.

\subsection{Temperature of the loaded water}

Temperature history of the loaded water with erythritol as PCM is presented in Fig. 12. The temperature history is obtained by solving ordinary differential equation of (6). From this figure, it can be observed that the temperature of the loaded water increases quickly once it is placed on the cooking vessel at 17:00. Temperature of the loaded water changes from $30^{\circ} \mathrm{C}$ to $100^{\circ} \mathrm{C}$ in about 3.5 hours. As a result of this heat transfer, the temperature of point $T_{1}$ is decreasing from $129^{\circ} \mathrm{C}$ to $100^{\circ} \mathrm{C}$. Moreover, point $T_{2}$ whose position far away from the inner surface, the temperature begins to decrease at 19:30. Finally, after 4 hours of cooking, temperature of the PCM and the loaded water is decreasing together, and after 24 hours, their temperatures are $81.5^{\circ} \mathrm{C}$ and $76^{\circ} \mathrm{C}$ respectively. These numerical results are confirmed by the experimental results conducted by Sharma et al. (2005). Further, by using other selected PCMs, the temperature of the loaded water can not reach the boiling temperature of $100^{\circ} \mathrm{C}$.

Fig. 13 shows three-dimensional temperature distribution of PCM storage with erythritol as thermal energy storage at $t=5.6$ hours. The figure reveals that most of the erythritol has temperature between 110$118^{\circ} \mathrm{C}$. It can be seen that most of the temperature of erythritol approaches its melting point. It indicates that a PCM for storing heat energy should have high latent heat of fusion so that it can prescribe temperature at the melting point. It can be observed from Fig. 10 and also Fig. 11 that erythritol can maintain the temperature at its melting point from 12:00 to $19: 30$.

\section{Conclusion}

Numerical simulation to evaluate thermal performance of various phase change materials used as thermal energy storage in a solar cooker has been successfully conducted. The numerical scheme to solve phase change problem has been verified and the numerical result for one-dimensional case confirms the analytical solution with the accuracy of melt front is more than 99\%. According to the simulation results, it is obtained that magnesium chloride hexahydrate has the highest total stored energy but by the Stefan number, erythritol has the highest stored energy in the form of latent heat of fusion. The influence of different of PCMs does not affect significantly to the change of energy stored in heat transfer fluid. The phase change material with the best thermal performance during the first 2.5 hours of energy extraction is shown by erythritol. Magnesium nitrate hexahydrate is effective only for one hour with the PCM storage temperature around 121$128^{\circ} \mathrm{C}$. Moreover, magnesium chloride hexahydrate can maintain temperature of PCM storage in the range of $110-116.7^{\circ} \mathrm{C}$ for more than 4 hours. Among the PCMs that have been tested, it is only erythritol that can cook $10 \mathrm{~kg}$ of the loaded water until it reaches the boiling 
temperature of $100^{\circ} \mathrm{C}$ within 3.5 hours. Suggestion for the future research is conducting numerical simulation to evaluate thermal performance of a solar cooker with erythritol as thermal energy storage and vegetables oil as heat transfer fluid.

\section{References}

Alexiades, V. \& Solomon, A.D. (1981) Mathematical Modeling of Melting and Freezing Processes. Hemisphere Publishing Corporation, Washington DC.

Agyenim, F., Hewitt, N., Eames, P., \& Smyth, M. (2010) A review of materials, heat transfer and phase change problem formulation for latent heat thermal energy storage systems (LHTESS). Renewable and Sustainable Energy Reviews, 14(2), 615-628.

Buddhi, D. \& Sahoo, L.K. (1997) Solar cooker with latent storage: Design and experimental testing. Energy Conservation and Management, 38(5), 493-498.

Buddhi, D., Sharma, S.D., \& Sharma, A. (2003) Thermal performance evaluation of a latent heat storage unit for late evening cooking in a solar cooker having three reflectors. Energy Conservation and Management, 44(6), 809-817.

Chen, C.R., Sharma, A., Tyagi, S.K., \& Buddhi, D. (2008) Numerical heat transfer studies of PCMs used in a box-type solar cooker. Renewable Energy, 33(5), 1121-1129.

Choi, J.C. \& Kim, S.D. (1992) Heat-transfer characteristic of latent heat storage system using $\mathrm{MgCl}_{2} \cdot 6 \mathrm{H}_{2} \mathrm{O}$. Energy, 17(12), 1153-1164.

Costa, M., Buddhi, D., \& Oliva, A. (1998) Numerical simulation of a latent heat thermal energy storage system with enhanced heat conduction. Energy Conservation and Management, 39(3), 319330 .

Domanski, R., El-Sebaii, A.A., \& Jaworski, M. (1995) Cooking during offsunshine hours using PCMs as storage media. Energy, 20(7), 607616.

Esen, M. \& Ayhan, T. (1996) Development of model compatible with solar assisted cylindrical energy storage tank ans variation of stored energy with time for different phase change materials. Energy Conversion and Management, 37(12), 1775-1785.

Esen, A. \& Kutluay, S. (2004) A numerical solution of the Stefan problem with a Neumann-type boundary condition by enthalpy method. Applied Mathematics and Computation, 148(2), 321-329.

Gong, Z., \& Mujumdar, A.S. (1997) Finite-element analysis of cycle heat transfer in a shell-and-tube latent heat energy storage exchanger. Applied Thermal Engineering, 17(6), 583-591.
Handayani, N.A. \& Ariyanti, D. (2012) Potency of solar energy applications in Indonesia. International Journal of Renewable Energy Development, 1(2), 33-38.

Kanimozhi, B., Sanandharya, K., Anand, S., \& Kumar, S. (2015) Experimental study on solar cooker using phase change materials. Applied Mechanics and Materials, 766-767, 463-467.

Khalifa, A.M.A., Taha, M.M.A., \& Akyurt, M. (1987) Design, simulation, and testing of a new concentrating type solar cooker. Solar Energy, 38(2), 79-88.

Muthusivagami, R.M., Velraj, R., \& Sethumadhavan, R. (2010) Solar cookers with and without thermal storage--A review. Renewable and Sustainable Energy Reviews, 14(2), 691-701.

Najemi, S.D. \& Boroushaki, M. (2016) Design, analysis and optimization of a solar dish/stirling system. International Journal of Renewable Energy Development, 5(1), 33-42.

Peng, D. \& Chen, Z. (2009) Numerical simulation of phase change heat transfer of a solar flat-plate collector with energy storage. Building Simulation, 2(4), 273-280.

Ravishankar, S., Nagarajan, P.K., Vijayakumar, D., \& Jawahar, M.K. (2013) Phase material on augmentation of fresh water production using pyramid solar still. International Journal of Renewable Energy Development, 2(3), 115-120.

Sharma, A., Tyagi, V.V., Chen, C.R., Buddhi, D. (2009) Review on thermal energy storage with phase change materials and applications. Renewable and Sustainable Energy Reviews, 13(2), 318-345.

Sharma, S.D., Buddhi, D., Sawhney, R.L., \& Sharma, A. (2000) Design development and performance evaluation of a latent heat unit for evening cooking in a solar cooker. Energy Conservation Management, 41(14), 1497-1508.

Sharma, S.D., Iwata, T., Kitano, H., \& Sagara, K. (2005) Thermal performance of solar cooker base on an evacuated tube solar collector with a PCM storage unit. Solar Energy, 78(3), 416-426.

Singh, H., Saini, K., \& Yadav, A. (2015) Experimental comparison of different heat transfer fluid for thermal performance of a solar cooker based on evacuated tube collector. Environment, Development and Sustainability, 17(3), 497-511.

Tarwidi, D., \& Pudjaprasetya, S. R. (2013). Godunov method for Stefan problems with enthalpy formulations. East Asian Journal on Applied Mathematics, 3(02), 107-119.

Tarwidi, D. (2015). Modeling and numerical simulation of solar cooker with PCM as thermal energy storage. In Information and Communication Technology (ICoICT), 2015 3rd International Conference on (pp. 584-589). IEEE.

Voller, V.R. \& Cross, M. (1981) Accurate solutions of moving boundary problems using the enthalpy method. International Journal of Heat and Mass Transfer, 24(3), 545-556.

Voller, V.R. \& Shadabi, L. (1984) Enthalpy methods for tracking a phase change boundary in two dimensions. International Communications in Heat and Mass Transfer, 11(3), 239-249. 